\title{
LA GUERRA DE LOS TREINTA AÑOS. UNA VISIÓN DESDE LA MONARQUÍA HISPÁNICA
}

\author{
Fernando Negredo Del Cerro
}

\author{
Madrid, Editorial Síntesis, 2016, 366 páginas. \\ ISBN: 978-84-9077-278-2
}

Quién no sabe algo de la guerra de los Treinta Años, de esa primera gran guerra europea como se la ha considerado, de su origen, espacios, etapas, principales batallas y protagonistas, de su desenlace y consecuencias. Sobre todo de su origen, situado sin duda, al menos en su momento más remoto, en el desarrollo de la paz de Augsburgo de 1555 que solo había acrecentado el odio entre católicos y luteranos al establecer que los príncipes alemanes -en número aproximado de trescientos sesenta- podían elegir en sus señoríos la religión luterana o católica de acuerdo con su conciencia y el conocido principio cuius regio, eius religio; los luteranos, conservar el territorio que habían tomado a la Iglesia católica desde la paz de Passau de 1552, y los obispos de la Iglesia católica que se convirtiesen al luteranismo tenían que entregar su diócesis.

Durante la segunda mitad del Quinientos las tensiones religiosas se intensifican, ya que los obispos se niegan a abandonar sus obispados. De hecho, los términos del tratado de Augsburgo fueron utilizados para un resurgimiento del poder católico. Las tensiones y resentimientos entre católicos y protestantes no hacen sino acrecentarse desde la firma del tratado, y en muchos lugares de Alemania se destruyen iglesias protestantes y surgen limitaciones y obstáculos al culto protestante. A la disminución de estas tensiones no ayudó nada el calvinismo que se extiende por toda Alemania, y cuya exclusión, junto a los anabaptistas, de las congregaciones protegidas específicamente en la paz de Augsburgo, contribuirá al posterior conflicto, lo que añade otra religión a la disputa pues los católicos de Europa central, los Habsburgo de Austria o los reyes de Polonia, están tratando de restaurar el poder del catolicismo. En este juego político los Habsburgo desean sobre todo extender su poder, así que a veces están dispuestos a transigir y permitir el protestantismo. A la larga esto incrementó las tensiones, pues, en este contexto, el emperador del Sacro Imperio Romano Germánico (SIRG en lo sucesivo) Rodolfo II y su hermano y sucesor Matías I no practican una política católica agresiva, al preferir incrementar el poder y las posesiones de los Habsburgo, cierta tolerancia religiosa que permite que diferentes religiones se extiendan y choquen libremente entre sí. Más al norte, Suecia y Dinamarca son países de confesión luterana. Estas tensiones estallan con violencia en la ciudad alemana de 
Donauwörth en 1606, cuando la mayoría luterana obstaculiza los intentos de los residentes católicos de hacer una procesión provocando así una revuelta violenta. Los católicos de la ciudad solicitan en su apoyo la intervención del duque Maximiliano I de Baviera. Cesada esta violencia, en Alemania los calvinistas, cuya religión está aún en sus comienzos y constituyen una minoría, se sienten amenazados y se agrupan en la Liga de la Unión Evangélica o Liga Protestante, creada en 1608 bajo el liderazgo del príncipe elector del Palatinado Federico IV, uno de los estados que España deseaba para sí a fin de proteger el camino español. A aquella unión los católicos responden con la Liga Católica bajo la jefatura del duque Maximiliano I. El emperador del SIRG y rey de Bohemia Matías de Habsburgo fallece en 1619 testando en favor de su primo hermano Fernando III de Estiria; quien convertido en Fernando II como rey de Bohemia y emperador, convencido católico y educado por los jesuitas, y dispuesto a restaurar el catolicismo, solo gana impopularidad en Bohemia, predominantemente calvinista, y, sobre todo, su rechazo, el detonante de la guerra de los Treinta Años.

A la problemática religiosa se une también la económico-política por cuanto a comienzos del Seiscientos se incrementan las tensiones entre las naciones de Europa, porque varias de ellas están interesadas en los principados alemanes aunque por distintas razones: España, porque el Habsburgo Felipe III tiene territorios alrededor de la frontera occidental de los Estados alemanes como Flandes y el Franco Condado; Francia, porque desea recuperar la hegemonía a costa de los Austrias; y Suecia y Dinamarca, por las ventajas económicas que les reportarían los territorios germánicos ribereños del Báltico.

Con la defenestración de Praga de 1618 se desencadena la guerra de los Treinta Años, que en sus principales etapas, desde la revuelta bohemia (1618-1625) a la intervención francesa (1636-1648), pasando por la fases danesa y la sueca (1625-1629, 1630-1635, respectivamente) y por supuesto su conclusión en la firma de las paces de Westfalia en 1648; sus batallas de Montaña Blanca, Nördlingen o Rocroi como hitos inolvidables; o las figuras de Condé, Gustavo Adolfo de Suecia, Richelieu, Olivares, Galasso, Oxenstierna, Turena, Wallenstein o Tilly como sus principales protagonistas, entre otros, acarreó la intervención de la mayoría de las grandes potencias europeas de la época y marcará el futuro del conjunto de Europa en los siglos posteriores. Porque en verdad lo que inicialmente se trata de un conflicto político entre Estados partidarios de la reforma y la contrarreforma dentro del propio SIRG, la intervención paulatina de las distintas potencias europeas convirtió gradualmente el conflicto en una guerra general por toda Europa por motivaciones religiosas pero también económicas y políticas pues con no poca 
frecuencia las primeras solo sirvieron de envoltorio y pretexto a las segundas. Terminada en las paces de Westfalia y Pirineos, como su correlato e indispensable epílogo, la guerra de los Treinta Años supuso el punto culminante de la rivalidad entre Francia y los territorios de los Habsburgo, en general, y de la Monarquía hispánica en particular, por la hegemonía en Europa, y que conducirá, en años posteriores, a nuevas guerras entre ambas potencias al no resolverse durante mucho tiempo los conflictos que la generaron. Y también la devastación y desolación como patentes consecuencias: Lugares enteros esquilmados por los ejércitos, en su gran mayoría de mercenarios y casi siempre necesitados de suministros; desaparición de infraestructuras y sitios habitados -solo los ejércitos suecos destruyeron durante la guerra unos dos mil castillos, dieciocho mil villas y mil quinientos pueblos en Alemania-; bancarrotas en muchas de las potencias implicadas; y considerable reducción de población por los continuos episodios de hambrunas y enfermedades que diezmaron la población civil de los Países Bajos e Italia y, sobre todo, del SIRG en un 30\% de media, porque en Brandeburgo se llegó al 50\%, en otras regiones incluso a dos tercios, la población masculina en Alemania disminuyó a la mitad, y en los países checos la población cayó en un tercio por guerra, hambre, enfermedades y expulsión masiva de checos protestantes.

A partir del magnífico y útil libro del profesor Negredo del Cerro ya nadie podrá decir que no conoce a la perfección la guerra de los Treinta Años porque de todo lo indicado habla y trata su obra, y además con detalle, hondura y precisión, sentido crítico e indudable profesionalidad.

Efectivamente, en el muy bien pensado, estructurado y equilibrado esquema que le guía y han guiado y articulado las cinco partes y dos capítulos por cada una en que el autor organiza la obra, lineal como debe ser en lo histórico, y por ende coincidentes con las antedichas distintas fases del conflicto, va desgranando cada una de las motivaciones, avatares, hechos, protagonistas y desenlace del mismo, desde su inicio hasta su conclusión. Esto es: La guerra de los Treinta Años en perspectiva y el SIRG hacia el comienzo de la conflagración, un estado de la cuestión y de la situación del espacio inicial de la contienda, los contenidos de la primera parte o introducción; la defenestración de Praga y la ruptura del orden constitucional, y los intereses particulares y miedos generales -los de la segunda, dedicada a la sublevación de Bohemia y la progresiva división de Europa entre 1618 y 1627-, la conjunción de escenarios por las intervenciones de Dinamarca y Suecia -o parte tercera, centrada en la intransigencia confesional y la expansión del conflicto desde 1628 a 1634-, la etapa francesa o situación tras Nördlingen y la delimitación cada vez mayor de los bandos, hasta el punto de iniciarse realmente otro tipo de conflagración, así como los 
momentos cruciales entre los años finales de la década de los treinta y el comienzo de los cuarenta del Seiscientos -los capítulos de la parte cuarta, dirigida a analizar los esfuerzos por una paz imposible que solo conduce a la guerra total entre 1635 y 1642-, y las operaciones militares del último quinquenio tras Rocroi y las paces de Westfalia, los de la quinta y última parte de la obra, dirigida a explicar el largo camino hacia el fin de la guerra entre 1643 y 1648. Una conclusión -en realidad, la propuesta explicativa global del autor al conflicto porque atiende a todas sus consecuencias-, tres anexos sobre la genealogía de los Habsburgo, las relaciones familiares entre los principales príncipes reformados y doce interesantes textos para que el lector pueda implicarse directa y personalmente en la etapa historiada a través de los mismos, y la bibliografía, cierran esta obra, indudablemente ya todo un referente de inexcusable consulta para quien desee conocer su periodo y temática.

Pero con ser todo esto enormemente importante por clarificar un conflicto, per se, ya muy complicado y complejo, es mucho más que eso el libro del profesor Negredo. Porque no solo se limita a lo estrictamente bélico o militar como podría esperarse de su temática. Porque además de prestar atención a las cuestiones internas de los distintos territorios por la implicación o actuación también de los factores locales -en especial, en el SIRG por la presencia del nacionalismo y del autoritarismo propios del Estado de la primera Edad Moderna-, a la relación entre política interna y externa -como hace en el caso de la Monarquía Hispánica, donde dicha vinculación es clarísima, sobre todo en la década de los cuarenta del siglo XVII-, al clero y la ideología religiosa como justificativa del conflicto en los dos bandos, al valor obvio de la religión en el Antiguo Régimen -sin olvidar que a veces también lo religioso es político- pero también de otros factores en la guerra como los geoestratégicos, políticos, económicos, sociales y aun culturales, analiza tres aspectos que, a mi juicio, son especialmente sobresalientes de su aportación, a saber: La historiografía; el enfoque de la obra, recogido en su subtítulo y de donde procede lo que considero su mayor aportación, la desmitificación de muchos tópicos, ideas preconcebidas y prejuicios; y la significación de las paces de Westfalia.

En cuanto a lo primero, cuestionando a veces las aportaciones clásicas e incidiendo en otras más recientes o que se ajustan más a lo que mueve y defiende el profesor Negredo, por, sobre todo, orillar el papel de la Monarquía Hispánica en el conflicto, sencillamente hay un antes y un después de esta obra por el orden, en historiadores, contribuciones y perspectivas, que presenta. Por lo que respecta a lo segundo, sin duda el gran mérito del libro es situar -mejor dicho, resituar- el papel de la Monarquía Hispánica en la conflagración que media el Seiscientos, centrándolo, 
colocándolo, donde debía estar por haber sido desplazado o no tenido en cuenta por cierta historiografía, y de donde deriva toda esa importante labor de desmitificación del conflicto, mucha y de tan variada índole que sale constantemente en la obra por recorrerla en todo momento y ser parte esencial de la misma, y que podrían ejemplificar, por simbólicas, la escasa atención dada a la situación de la propia familia imperial, el enfrentamiento entre la libertad de los príncipes y el absolutismo imperial de los Habsburgo, la frecuente intuición política certera de Madrid frente a Viena, la exagerada importancia dada al camino español, la comprensión casi siempre cierta y acertada por parte de Madrid de las intenciones aviesas y expansionistas de París, el ascendiente de Suecia sobre Francia, las incorrecciones en datos sobre pérdidas y denominaciones de micro-etapas y batallas; la presencia de la Monarquía hispánica en el SIRG; la necesidad de redefinir el papel de la propaganda, de ir a las cuestiones de fondo, con frecuencia ocultas y ocultadas por los éxitos o fracasos puntuales; de ponderar más la razón de Estado frente a las iniciativas particulares; o la sobredimensión de Nördlingen, Rocroi, la cuestión holandesa para Madrid, y las implicaciones territoriales reales de Westfalia para la Monarquía hispánica extrapeninsular. En definitiva, romper ese frecuente intento de estudiar la guerra alemana sin contar con Madrid, en palabras del autor, todo "un ejercicio de historia ficción quizá atractivo pero en absoluto riguroso" (p. 240).

Por último, y también desmitificando, esta obra define bien la problemática causante del conflicto, huyendo de interpretaciones únicas, sesgadas y simplistas, y, por ende, uniendo lo religioso a otras distintas y muy variadas dimensiones mucho más materiales que asimismo lo produjeron y que en modo alguno pueden escamotearse; también sus consecuencias; y, sobre todo, ubica bien la importancia, y en especial transcendencia, de las paces de Westfalia, contextualizando adecuadamente su proyección ulterior en el concierto alemán y en el orden internacional, lejos de un presentismo mal entendido y empleado.

Todo ello hace de este un gran libro, muy útil y clarificador para la temática que trata, e innovador porque, por sobre todo su ya comentado enfoque, hace verdadera aportación al conocimiento modernista. Obra indispensable de consulta para su temática y realizada con la maestría de quien sabe unir sencillez y claridad a rigor para conducir al lector por un asunto complicado y complejo, como ya dije, y con no pocos tecnicismos bélicos y militares, y a la que en modo alguno afecta la ausencia de una cartografía que sin duda vendría bien para completar las referencias precisas al respecto que constan en el texto, satisface también otro fin muy importante e intrínseco al mismo impulso editorial 
que lo motiva, atender el ahora inexcusable cometido de la divulgación, difusión científica y transferencia del conocimiento, como ahora se dice y proclama, para llevar este periodo de la historia de Europa a expertos, estudiantes, curiosos y público en general.

Ma Soledad Gómez Navarro

Universidad de Córdoba 